\title{
As Representações Sociais das Famílias das Crianças Hospitalizadas e suas Implicações no Cotidiano Familiar
}

\section{Social Representations of Hospitalized Children'S Families: Impact on Family Routine}

\author{
Melissa Ferreira Portes* \\ Camila Pasetto** \\ Laura Gorski** \\ Elizabete Araújo Eduardo***
}

\begin{abstract}
Resumo: Este artigo apresenta as representações sociais de mulheres que acompanharam seus filhos durante o período de hospitalização em um hospital público infantil, evidenciando as implicações desse período no cotidiano das famílias. Trata-se de uma pesquisa descritiva que utilizou como técnica de coleta a entrevista semiestruturada com amostra intencional e a análise de conteúdo como método para interpretação dos dados. As categorias elencadas na pesquisa permitiram conhecer a realidade socioeconômica e cultural das famílias, apontando as situações de vulnerabilidade em que as mesmas se encontram, sendo possível ressignificar o exercício profissional que desponta como um terreno fértil para o trabalho com famílias em uma perspectiva humanizadora, ética, criativa e propositiva. O estudo provocou um repensar nas concepções de família que subsidiam a construção de metodologias de trabalho, despertando o desejo de resgatar, tanto na intervenção, quanto na investigação da prática social, a centralidade do sujeito.
\end{abstract}

Palavras-chave: Representações sociais. Hospitalização. Cotidiano.

\begin{abstract}
This paper discusses the social representations of women who accompanied their children during hospitalization in a children'spublic hospital, highlighting its impact on family routine. It is a descriptive study that used semistructure interviews as a data collection instrument and a content analysis approach for its interpretation. The categories emerged from the research show the socioeconomic and cultural profile of the families as well as their vulnerable situations. The study demonstrates that the professional practice is a promising field that should be performed according to a human, ethical, creative and proactive perspective. The study motivated considerations on conceptions of family that subsidy the construction of work methodologies that aim to highlight the central aspect of the participants not only in the intervention, but also in the investigations of social practices.
\end{abstract}

Keywords: Social representations. Hospitalization. Routine.

"Assistente Social do Hospital Infantil Waldemar Monastier e professora do Curso de Serviço Social das Faculdades Integradas do Brasil-UNIBRASIL. E-mail: melissaportes2010@gmail.com

"Assistente Social do Hospital Infantil Waldemar Monastier e membro do Núcleo Estudo Ensino e Pesquisa (NEEPS). E-mail: camilapasetto@sesa.pr.gov.br

***Assistente Social do Hospital Infantil Waldemar Monastier e membro do Núcleo Estudo Ensino e Pesquisa (NEEPS). E-mail: lauragorski@sesa.pr.gov.br

***** Enfermeira. Especialista em Saúde Pública. Mestranda do Programa de Pós-Graduação em Prática de Enfermagem da UFPR. Membro do Núcleo Estudo Ensino e Pesquisa (NEEPS).E-mail: elizabeteeduardo@sesa.pr.gov.br 


\section{Introdução}

O ambiente hospitalar é um espaço caracterizado, em sua particularidade, por anseios de cura e recuperação, tendo presentes sentimentos de medo e insegurança. As famílias que estão prestes a adentrar em um processo de hospitalização, além de apresentarem os anseios e sentimentos comuns a esse período, trazem consigo histórias e modos de vida que precisam ser acolhidos e tratados com muita afinação, através de uma abordagem baseada na horizontalidade, objetivando uma recepção mais humana e acolhedora.

O Serviço Social hospitalar desenvolve sua prática em consonância com o projeto éticopolítico da profissão, buscando através de ações mediatas e reflexivas superar a ação tarefeira e pragmática. Em sua intervenção busca desvelar as contradições presentes na realidade em que atua, descortinando a condição de vida das famílias atendidas para construir estratégias de enfrentamento dessa realidade.

No Hospital Infantil Waldemar Monastier (HI), hospital público paranaense especializado no atendimento de crianças e adolescentes, o Serviço Social realiza o acolhimento dos pacientes e de seus familiares, além de intervir em diferentes demandas que emergem de todos os setores da instituição.

A observação sistemática, o planejamento da intervenção, a abordagem realizada nos leitos junto às famílias e o levantamento do perfil socioeconômico das mesmas têm possibilitado constantemente a ampliação do conhecimento dos assistentes sociais sobre a realidade hospitalar e, de forma mais específica, sobre o cotidiano da criança hospitalizada e de sua família.

Durante os acolhimentos e abordagens realizados junto aos acompanhantes verificou-se que, na maioria das situações, é a mulher quem acompanha a criança no processo de hospitalização. Como descreve Menezes (2007, p. 88),

Elas são mães, donas-de-casa, trabalhadoras e dinâmicas, mas pouco visíveis na sociedade da qual fazem parte, ainda em sua maioria excluídas da plena vivência como cidadãs participantes, atuantes e presentes no encaminhamento de suas ações no e para o mundo.
A importância da presença de um acompanhante não se resume apenas à sua presença física e no auxílio que presta nos procedimentos, mas também porque contribui para uma aceleração do processo de recuperação do paciente acompanhado, através do cuidado. Tratando de cuidado, Boff (2005, p.31) afirma que o mesmo implica acolhimento, respeito e a capacidade de entrar em sintonia com o outro, características que historicamente foram vinculadas ao sexo feminino, por tratar-se de uma figura maternal, afetiva e acolhedora.

As mulheres possuíam a hegemonia histórico-social e davam ao feminino, que não é exclusivo delas (os homens são também portadores de feminino), uma expressão tão profunda, que ficou na memória permanente da humanidade através de grandes símbolos, sonhos e arquétipos do feminino na cultura e no inconsciente coletivo.

As famílias são constituídas por diferentes valores e costumes, expressando diferentes demandas que exigem dos assistentes sociais a construção de estratégias conforme a particularidade de cada família. Nesse universo emergiu o interesse de investigar de forma mais aprofundada o cotidiano familiar, conhecendo os modos de vida das famílias e as interfaces com a condição de saúde da criança.

Neste artigo serão compreendidas as representações sociais expressas por 06 (seis) muIheres ${ }^{1}$ que acompanharam seus filhos durante o período de hospitalização, assim como as implicações dessas representações no cotidiano familiar.

Considerando a representação social como uma "[...] expressão do conhecimento reconstruído pelo sujeito a respeito da sua realidade cotidiana, considerando as determinações sociais, históricas e culturais presentes no contexto em que se insere" (BOURGUIGNON, 2001, p.82), buscou-se: conhecer as condições de vida da família; desvendar as implicações da hospitalização no seu cotidiano; apontar as necessidades e dificuldades da cuidadora com relação aos cuidados com o infante; verificar o

\footnotetext{
${ }^{1}$ Identificação das entrevistadas através de nomes de mulheres que marcaram momentos históricos no Brasil: Anita Garibaldi, Bertha Lutz, Olga Benário, Maria Quitéria, Maria da Penha e Nísia Floresta. Uma forma de reconhecimento pelas suas histórias de vida marcadas pela luta, perseverança e resistência.
} 
acompanhamento pela rede socioassistencial e investigar a necessidade do acionamento da rede durante o período de hospitalização.

A população atendida pelo hospital é rotativa, portanto, passível de alteração. Para definição da amostra foi escolhido mês de dez/2011, no qual foram realizados 276 internamentos no hospital. A amostra da pesquisa é constituída por 06 (seis) acompanhantes de crianças hospitalizadas nos setores: Internação 1 e 2 . A escolha foi intencional, considerando: acompanhantes que permanecem maior período no hospital e famílias que apresentam vulnerabilidade social e que já estão sendo atendidas pela rede socioassistencial do município de origem.

Por possibilitar aproximação direta e prolongada com os sujeitos, a pesquisa escolhida foi a qualitativa. A abordagem qualitativa tem caráter descritivo e considera o dizível e o indizível, ou seja, o que é oralmente expresso, e também gestos, linguagem corporal e os símbolos. Nesse caso, o pesquisador deve se atentar ao "significado" que as pessoas dão aos objetos, às situações e à sua vida. Apreender a "perspectiva dos participantes" - as diferentes percepções dos sujeitos sobre as questões.

Também foram utilizados dados quantitativos, levando em consideração o perfil socioeconômico e cultural das famílias. As pesquisas quantitativas e qualitativas oferecem perspectivas diferentes, mas não são necessariamente pólos opostos. De fato, elementos de ambas as abordagens podem ser usados conjuntamente em estudos mistos, para fornecer mais informações do que poderia se obter utilizando um dos métodos isoladamente.

Utilizou-se a entrevista semiestruturada, "a qual combina perguntas fechadas e abertas, em que o entrevistado tem a possibilidade de discorrer sobre o tema em questão sem se prender à indagação formulada." (MINAYO, 2007, p.64). As entrevistas foram individuais, em salas privativas, garantindo o sigilo e a confiabilidade.

Tendo como base os objetivos do trabalho, utilizou-se a pesquisa descritiva, para auxiliar nas descrições dos fenômenos que se apresentaram ao longo da pesquisa. Uma das suas características mais significativas, lembra Gil (1999, p.44), estão na utilização de técnicas padronizadas de coleta de dados, tais como o questionário e a observação sistemática. Ela es- tuda a distribuição por idade, sexo, procedência, nível de escolaridade, estado de saúde física e mental, levanta opiniões, atitudes e crenças de uma população. Cabe destacar que a pesquisa descritiva, juntamente com a exploratória, é habitualmente utilizada pelos pesquisadores sociais preocupados com a atuação prática.

Após levantamento da coleta de dados, os mesmos passaram por um processo de análise, através do método de análise de conteúdo.

A análise de conteúdo é um tema central para todas as ciências humanas e com o transcurso do tempo tem-se transformado em um instrumento importante para o estudo da interação entre os indivíduos. Ou seja, o estudo dos símbolos e das características da comunicação é básico para compreender o homem, sua história, seu pensamento, sua arte e suas instituições. (RICHARDSON, 1985, p.175).

Assim, a estrutura do texto está organizada a partir das categorias emergentes da realidade estudada: família e seus retratos; vulnerabilidade social no cotidiano familiar e os significados e implicações da hospitalização no cotidiano familiar.

\section{Família e seus retratos}

Ao tratar de família é fundamental considerar a reflexão da afirmação de Sarti, ao declarar que

Pensar a família como uma realidade que se
constitui pelo discurso sobre si própria, inter-
nalizado pelos sujeitos, é uma forma de bus-
car uma definição que não se antecipe à sua
própria realidade, mas que nos permita pen-
sar como ela se constrói, constrói sua noção
de si, supondo evidentemente que isto se faz
em cultura, dentro, portanto, dos parâmetros
coletivos do tempo e do espaço em que vive-
mos, que ordenam as relações de parentesco
(entre irmãos, entre pais e filhos, entre marido
e mulher). Sabemos que não há realidade hu-
mana exterior à cultura, uma vez que os seres
humanos se constituem em cultura, portanto,
simbolicamente. (2008, p. 27).

Ao fazer uma aproximação da acompanhante do paciente inicia-se um processo dialógico, no qual se percebe as diversas angústias e preocupações que assolam sua vida, tanto no trato daqueles que estão hospitalizados, quanto no que se refere ao abandono da rotina devido 
ao processo de hospitalização. Cabe à pesquisa desvendar tais anseios, preocupações e buscar compreender a realidade vivenciada por essas famílias a partir de suas próprias histórias, considerando que "Dentro das referências sociais e culturais de nossa época e de nossa sociedade, cada família terá uma versão de sua história, a qual dá significado à experiência vivida." (SARTI, 2008, p. 26).

Diante do conhecimento de que "[...] trabalhar com famílias requer a abertura para uma escuta, a fim de localizar os pontos de vulnerabilidade, mas também os recursos disponíveis" (SARTI, 2008, p. 26) inicia-se a apresentação do levantamento do perfil socioeconômico realizado pela pesquisa, que possibilitou traçar o perfil das mulheres entrevistadas e compreender nas análises posteriores as situações de vulnerabilidades sociais vivenciadas por elas e seus familiares, bem como as estratégias de sobrevivência utilizadas pelas mesmas, considerando o período de hospitalização de seus filhos.

Diante da predominância do sexo feminino como acompanhantes dos pacientes em hospitais, destaca-se que todos os sujeitos desta pesquisa são representados pelas próprias mães das crianças e/ou adolescentes hospitalizados. Mulheres que possuem idade correspondente à faixa etária dos 18 aos 32 anos, residentes em municípios do Estado do Paraná, em sua maioria pertencentes à região metropolitana de Curitiba.

Considerando o contexto familiar dessas mulheres, cabe destacar a família

... como expressão máxima da vida privada é lugar da intimidade, construção de sentidos e expressão de sentimentos, onde se exterioriza o sofrimento psíquico que a vida de todos nós põe e repõe. É percebida como nicho afetivo e de relações necessárias à socialização dos indivíduos, que assim desenvolvem o sentido de pertença a um campo relacional iniciador de relações includentes na própria vida em sociedade. È um campo de medição imprescindível. (CARVALHO, 2008, p.271).

Considerando a composição familiar dessas mulheres, destaca-se a abrangência da multiplicidade de arranjos familiares existentes. Arranjos que contemplam famílias monoparentais, famílias extensas e nucleares, famílias envoltas pela particularidade de suas rotinas, mas que contemplam de meios sociais semelhantes, envoltos pela vulnerabilidade social.

Das 06 (seis) mulheres entrevistadas, 03 (três) correspondem ao modelo nuclear, considerado como aquele composto pelos pais e seus filhos; 02 (duas) mulheres possuem sua composição familiar formada por elas mesmas e seus filhos, ou seja, um modelo de família monoparental; e a família extensa, representada por 01 (uma) das entrevistadas, é composta por diversos familiares, dentre eles os avós e tios da criança hospitalizada, além de seu pai e irmãos.

O número de moradores por domicílio vai de 03 (três) a 08 (oito) pessoas, considerando domicílios próprios e cedidos, estruturados com 03 (três) a 09 (nove) cômodos.

Ao indagar as condições dos domicílios, apenas 01 (uma) das mulheres afirmou ter domicílio localizado em área de risco. Das famílias entrevistadas, 05 (cinco) possuem água encanada, sendo que 04 (quatro) delas possuem tarifa reduzida em função de baixa renda; já a rede de esgoto faz parte da realidade de apenas 02 (duas) das famílias, sendo que as demais não possuem acesso à rede de esgoto, sendo o mesmo jogado a céu aberto.

Todos os domicílios possuem energia elétrica, sendo que 03 (três) das famílias possuem a tarifa reduzida em função de baixa renda; já a coleta de lixo é feita três vezes por semana no domicílio de 05 (cinco) famílias. Em apenas em 01 (um) dos domicílios o lixo é queimado no local.

Diante de tais composições e estruturas domiciliares, destaca-se a renda dessas famílias. Observou-se que das 06 (seis) famílias entrevistadas, 03 (três) recebem menos de um salário mínimo e as demais detêm uma renda de um a dois salários mínimos; renda que em sua maioria é alcançada por trabalhos temporários, sem vínculo formal com o contratante.

Importante observar que todos os filhos das mulheres entrevistadas fazem parte do Programa Bolsa Família, 04 (quatro) das famílias recebem também o auxílio do vale-leite e 03 (três) delas recebem cesta básica.

Tratando especificamente de seus filhos (hospitalizados ou não) apenas uma das entrevistadas relatou ter apenas um filho. Já as demais afirmaram ter de dois a sete, sendo que desses, nove são do sexo masculino e dez do sexo feminino. A faixa etária dos mesmos revela que nove

70 Emancipação, Ponta Grossa, 13, nEspecial: 67-78, 2013. Disponível em <http://www.revistas2.uepg.br/index.php/emancipacao> 
têm entre 1 a 5 anos; cinco de 6 a 10 anos; quatro de 11 a 15 anos e um menor de 1 ano.

Revela-se na faixa etária predominante a presença da primeira infância, crianças que necessitam de constante acompanhamento e que ainda são bastante dependentes de seus responsáveis, o que ao longo da pesquisa será relacionado às dificuldades do internamento.

Todos os filhos (as) das entrevistadas possuem a carteira de vacinação e utilizam o Sistema Único de Saúde, assim como os demais familiares, em casos de problemas de saúde.

Como afirma Trad

O debate em torno das transformações sociais que incidem sobre a família contemporânea e as especificidades deste processo no contexto brasileiro se reveste de valor estratégico no campo da saúde na atualidade. Nas últimas duas décadas, o enfoque familiar vem sendo adotado como eixo norteador de políticas e programas de saúde pública brasileira, particularmente no âmbito da atenção primária. $(2010$, p.28).

Entende-se que a política de saúde não se consolida solitariamente, mas articulada com as demais políticas sociais. Diariamente vivenciam-se situações que comprovam que a condição de saúde da criança depende das condições sociais (moradia, saneamento básico, alimentação, renda, acesso a serviços). A situação de vulnerabilidade social da família, em muitos casos, é fator desencadeador de doenças nas crianças e adolescentes, comprometendo seu desenvolvimento e sua saúde, conforme apontamentos das próximas categorias.

\section{Vulnerabilidade social no cotidiano familiar}

O perfil socioeconômico e cultural apresentado anteriormente permite evidenciar um cenário de desigualdade econômica e social que traz implicações perversas no cotidiano ${ }^{2}$ das famílias, uma vez que as mesmas encontram-se impossibilitadas de desenvolverem suas funções elementares de proteção social, de cuidado, de

\footnotetext{
${ }^{2} \mathrm{O}$ conceito de cotidiano adotado nessa pesquisa tem como referência os estudos de Agnes Heller (1970), que ao tratar sobre a estrutura $\mathrm{d}=0$ cotidiano afirma que a vida cotidiana é a vida de todo homem, do homem inteiro, que participa dela em todos os seus aspectos, em todos os seus sentidos.
}

socialização e de nutrição física e emocional. Esse cenário é reflexo do modelo econômico imperativo na atual sociedade, que se desenvolve de forma contraditória, possibilitando a emergência e o reconhecimento da questão social.

Para Carvalho e lamamoto (1991, p.77),

A questão social não é senão as expressões do processo de formação e desenvolvimento da classe operária e de seu ingresso no cenário político da sociedade, exigindo seu reconhecimento como classe por parte do empresariado e do Estado. É a manifestação no cotidiano da vida social, da contradição entre o proletariado e a burguesia, a qual passa a exigir outros tipos de intervenção, mais além da caridade e repressão.

A questão social pode se manifestar no cotidiano de diferentes formas e configura-se em uma multiplicidade de expressões, produzindo o acirramento das desigualdades sociais que se manifestam através da destituição dos direitos e da invisibilidade dos sujeitos sociais. A condição de privação, de pobreza e de fragilidade vivenciada pelas famílias contribui para a criação de situações de vulnerabilidade familiar, ameaçando a dignidade humana e qualquer possibilidade de emancipação social.

O perfil socioeconômico e cultural das famílias apresentado anteriormente evidencia a limitação existente na capacidade das mesmas enfrentar as situações sociais concretas devido à insuficiência da renda para suprir as necessidades básicas dos membros da família, fruto da precarização das condições de trabalho ou ausência dele, como também da carência de políticas sociais emancipadoras.

As expressões da questão social aparecem nos relatos dos sujeitos da pesquisa quando estes partilham suas histórias de vida e expõem as situações vivenciadas, marcadas pelo sofrimento, pelo sentimento de impotência frente aos problemas cotidianos e pelo adoecimento de todos os membros da família. O contexto de pobreza coloca as famílias em situação de risco pessoal e social, portanto, as torna vulneráveis. Segundo Kaztman, citado por Silva (2007, p.1), a vulnerabilidade não é o mesmo que pobreza, mas a inclui. Assim retira das famílias a condição de usufruir substantivamente dos direitos de cidadania (FRIEDMANN, 1996). 
Ao refletir sobre o conceito de vulnerabilidade social, Ambramovay entende o mesmo como

[...] resultado negativo da relação entre a disponibilidade dos recursos materiais ou simbólicos dos atores, sejam eles indivíduos ou grupos, e o acesso à estrutura de oportunidades sociais econômicas culturais que provêm do Estado, do mercado e da sociedade. Esse resultado se traduz em debilidades ou desvantagens para o emprego e mobilidade social dos atores. (2002, p.13).

É possível compreender que estar vulnerável, ainda que provisoriamente, interfere não só nas estruturas da vida (acesso aos bens e serviços), mas na construção da identidade individual e coletiva dos sujeitos e nas potencialidades humanas. A vulnerabilidade projeta sentimentos ligados ao fracasso, à insegurança, à fragilidade e ao não pertencimento.

Quando questionados sobre as dificuldades vivenciadas pela família, os sujeitos da pesquisa fizeram referência às situações de violência, de drogadição, de abuso sexual:

"Ele (companheiro) já me agrediu, depois que a mais nova nasceu diminuiu. A assistente social pegou meu marido usando droga, outra vez ela chegou na hora que ele ia me agredir. Quando ele está sob efeito da droga, nossa! Mas quando não está, fala que não lembra de nada. Ele é trabalhador, é pedreiro profissional, ganhava bem. Eu nunca fui de prender ele dentro de casa. Tenho dó do meu marido, quando ele não está sob efeito. Tenho medo quando ele está sob efeito. Ele tentou me bater esses dias, mas falei que ia tirar as crianças, chamar a polícia. Daí ele não fez nada. Ele parou de me agredir me bater, mas agora ele me agride por palavras.Se eu tivesse um serviço, eu dava um jeito pra arrumar uma casa.Tenho pena dele, ele deveria ter amor pelos filhos, mas com o efeito da droga ele pede para os filhos se afastarem.Onze anos convivendo com a pessoa. Há quatro anos que ele usa. Quando ele não usa ele é bom pai, bom marido, se preocupa com as crianças". (Anita Garibaldi)

(A droga) "Afeta tudo, né! Desde que nasci meu pai usa droga. Mas até uns quatro anos atrás ele trabalhava, nunca deixou faltar comida em casa. Daí ele começou fazer isso. Usa mais, não dorme.(Ele é violento?) Ele é e não é. Porque agora sim ele colocou na cabeça que minha mãe tá traindo ele. Aí torna a pessoa bem alucinada.(Como é o relacionamento familiar por conta disso?) Ah, ficam tudo apavoradas. A minha irmãzinha de 2 anos, na hora que vê a briga ela começa: 'Chama a polícia, chama a polícia'.(Ele bate nas crianças?) Não, nas crianças não.(E na sua mãe?) Ah, não. Só agressão verbal mesmo. (Sobre o irmão mais velho 14anos?) Não estuda porque ele se envolveu no mundo de traficantes. Não faz uso de droga. Às vezes ele para e depois volta.(E o Diego, (outro irmão da entrevistada, como ele é?) Ele estuda na $5^{a}$ série. Ele não se envolve com droga. Ele é o estranho. Porque ele não se envolveu com esse tipo de coisa, não fica na rua. Ele estuda, gosta de ficar em casa jogando videogame". (Bertha Lutz)

"Um monstro desse não merece visita quem faz isso com crianças (referência ao companheiro que abusou sexualmente de duas filhas). Ele judiava demais das crianças. Ele cainhava (negava) comida pras crianças. Batia nelas. Já tinha dificuldade com ele. Tudo que a gente queria tinha, mas ele era muito ruim. Eu já não sou de gritar com ele. Ele não sabia falar. Dava cada pontapé!No começo ele pareceu ser bom, depois que eu ganhei meu filho ele foi mostrando os traços dele.(O abuso sexual) Foi descoberto quando Fátima tinha 11 anos. Ela confiava né, era pai. Só que nessa confiança fui pega de surpresa. Ele começou a agradar demais a menina. Certo dia ele avisou que ia chegar mais tarde. Eu fui deitar e a menina ficou limpando a cozinha. Ele chegou perguntando de mim e ela disse que eu tava dormindo. Chamou a menina tapou a boca e começou a abusar. Depois disso, nós deixamos ela na casa de passagem um ano e meio". (Olga Benário)

Os relatos descrevem um quadro de negação e violação de direitos sociais, decorrente de uma débil intervenção estatal e de políticas sociais com características paternalistas e reformistas que não contribuem para alteração substancial das condições de vida das famílias. Ao contrário, as tornam mais dependentes da tutela governamental e menos competentes para acessar bens e serviços.

As situações partilhadas pelos sujeitos da pesquisa evidenciam também a insegurança presente na atual sociedade. 
As sociedades modernas são construídas sobre o terreno da insegurança, porque são sociedades de indivíduos que não encontram, nem em si mesmos, nem em seu entorno imediato, a capacidade de assegurar sua proteção (...). O sentimento de insegurança não é exatamente proporcional aos perigos reais que ameaçam a população. É antes um efeito de um desnível entre uma expectativa socialmente construída de proteções e as capacidades efetivas de uma determinada sociedade de colocá-las em prática. (CASTEL, 2005, p.9).

A questão do uso e do abuso de drogas e da violência configura-se em um risco social para essas famílias porque provoca um esgarçamento dos laços afetivos e dos vínculos familiares, enfraquecendo e limitando a construção de estratégias de enfrentamento, bem como o desenvolvimento da autonomia, competências e tomadas de decisões. Portanto, as situações/ eventos que vulnerabilizam as pessoas são determinados tanto pela natureza econômica como também por "fatores como a fragilização dos vínculos afetivo-relacionais e de pertencimento social(discriminações etárias, étnicas, de gênero ou por deficiência) ou vinculadas à violência, [...] a representação política, dentre outros." (Almeida, citado por BALSA, 2006, p.87).

As experiências vividas pelas famílias entrevistadas expressa a contradição existente entre o que se espera que as mesmas façam e se tornem (família idealizada) e o que realmente elas podem e conseguem fazer para romper com a condição de pobreza e vulnerabilidade (família real). Se por um lado entende-se que a família é o espaço indispensável para garantir a sobrevivência e proteção social dos seus membros (KALOUSTIAN; FERRARI, 1994), por outro se questiona a proteção social do Estado em relação a essas mesmas famílias, pois quem não está protegido e fortalecido não tem condições de cuidar, assistir e proteger. Para Miotto (2008), a família tem sido chamada para a responsabilização pela provisão das condições objetivas e subjetivas de sua vida, ocorrendo uma retração da responsabilidade do Estado com a proteção social dos membros da sociedade.

Das 06 (seis) famílias entrevistas, 03 (três) disseram ser acompanhadas pelo Conselho Tutelar do município de origem, sendo todas atendidas no Centro de Referência da Assistência
Social (CRAS). Uma delas é também atendida no Centro de Referência Especializado de Assistência Social (CREAS). E todas utilizam o Sistema Único de Saúde (SUS), através dos serviços regionalizados, tanto na atenção básica quanto na média complexidade. O acompanhamento pela rede socioassistencial de proteção elucida, mais uma vez, o contexto social e econômico no qual essas famílias estão mergulhadas. Neves pontua que "a rede de atendimento socioassistencial constitui em uma salvaguarda, para o apoio e a proteção social destinadas aos usuários dos serviços sociais, e que deverão receber dessa rede o amparo e o atendimento aos seus direitos." (2009, p.151).

Quando indagadas sobre suas expectativas de vida, seus anseios, projetos e sobre os cuidados que a família precisaria ter para que pudesse viver melhor, responderam:

"Queria um emprego melhor (trabalha na co-
Iheita de morango). Daí, a partir disso ficaria
melhor. Meu sonho é ter uma casinha da pre-
feitura, arrumar emprego com carteira regis-
trada". (Maria da Penha)

"Tinha que ter muito afeto na família. Minha família é muito desorganizada, não é unida, eu não tenho apoio da família, prefiro apoio de um desconhecido do que da família. Eu não tenho ânimo de sair em um parque, não tenho ânimo de pentear o cabelo. Minha irmã fala que eu tô acabada. Quero engordar, me cuidar, arrumar meus dentes, porque eles estão assim por desleixo meu". (Anita Garibaldi)

"Mudar de lugar, de casa, de bairro. Só eu não tem condições. Só uma pessoa trabalha". (Bertha Lutz)

"Putz, porque aquele homem não morre pra eu ser feliz?; Deus me perdoe desejar a morte do outro". (Olga Benário)

“A saúde do 'D' se ele fosse normal.... Se Deus ajudasse que ele pegasse saúde. Mudaria pra melhor. A gente sofre, pra lá e pra cá. É muito sofrimento". (Maria Quitéria)

"Não precisa mudar nada. Do que jeito que está, tá bom". (Nísia Floresta)

Os sonhos e aspirações estão intimamente correlacionados com os conflitos familiares e a privação econômica e social vivenciada por cada 
unidade doméstica. Maria da Penha aspira ter um lugar decente para morar, ter um trabalho digno, com carteira registrada. Mora sozinha com os filhos e é a única provedora. Anita, que convive com o companheiro que é usuário de crack e é violento, deseja que a família construa novas relações baseadas no afeto, na compreensão, na solidariedade. A família de Bertha é codependente do tráfico, tem seus passos seguidos e sua vida controlada por traficantes. O que ela quer? Mudar, ir para outro território. Mas reconhece a limitação do seu sonho. Olga, de família marcada pelo abuso sexual infantil, traz em seu desejo a vontade eminente de afastar o responsável pelos problemas e pelo adoecimento de família toda. Maria Quitéria, mãe de uma criança portadora de uma doença crônica, tem seu filho hospitalizado por longos períodos. Ela fica longe do marido, da família e é a única responsável pelos cuidados com o filho.

Os relatos estão carregados de conteúdo simbólico porque o que essas mulheres almejam vai além da superação da condição econômica e material em que vivem e que é importante para romper o ciclo da pobreza familiar. Mas elas também trazem em seus discursos a luta cotidiana pela liberdade, autonomia, vivacidade, pelo poder da voz e pela promoção da vida.

\section{Significado e implicações da hospitalização no cotidiano familiar}

Para melhor compreensão das experiências das famílias, constata-se a necessidade de estreitar a aproximação entre o profissional e as cuidadoras, pois existem informações que nem sempre são transmitidas em um primeiro momento, seja por falta de vínculos, por insegurança, ou ainda por ausência de uma postura profissional acolhedora. O que elas sentem, como sentem, como entendem, o significado que atribuem à situação que estão vivendo, como lidam com as informações que recebem, suas fragilidades e potencialidades, o conhecimento que têm construído e as implicações desses saberes, dessas vivências e desses significados no cotidiano familiar, constituem elementos imprescindíveis para a intervenção do Serviço Social, na medida em que o acionamento da rede socioassistencial e articulação com as demais políticas sociais dependem desses construtos.
As rotinas hospitalares e a alta rotatividade dos internamentos se tornam tão banalizadas que muitas vezes a equipe, inconscientemente, acaba desconsiderando os sentimentos que surgem com o período de hospitalização e o que este representa para o acompanhante.

Objetivando conhecer essa representação, buscou-se em alguns autores o conceito de representações sociais para compreender o universo explanado pelos sujeitos da pesquisa. Para Sá (2004, p.19) o termo representa "[...] um conjunto de fenômenos quanto o conceito que os engloba e a teoria construída para explicáIos, identificando um vasto campo de estudos psicossociológicos."

Arruda (2002) afirma que

A Teoria das Representações Sociais operacionalizava um conceito para trabalhar com o pensamento social em sua dinâmica e em sua diversidade. Partia da premissa de que existem formas diferentes de conhecer e de se comunicar, guiadas por objetivos diferentes, formas que são móveis. (p. 129-130).

\section{E Moscovici (2003) declara que esta é}

Uma teoria concebida para responder questões específicas com respeito a crenças e vínculos sociais e para descobrir novos fenômenos. A teoria das representações sociais está interessada, por um lado, em questões de vínculos sociais e da ação e, por outro lado, com o conhecimento social, comunicação e linguagem. (p.380).

Diante de tais conceituações, cabe a análise dos dados que envolvem a complexidade das representações sociais construídas pelas mulheres participantes na pesquisa.

Das 06 (seis) mulheres entrevistadas, 04 (quatro) já haviam acompanhado criança ou adolescente durante algum período de hospitalização. Apenas 02 (duas) delas nunca haviam passado por essa situação.

Para essas mulheres a hospitalização de seus filhos representa uma miríade de sentimentos manifestados através da compreensão de que aquilo será algo bom para ele, mas, ao mesmo tempo, conturbada pelo sofrimento e desgaste desse período. Essa multiplicidade de emoções e sentimentos (medo, angústia, incerteza, impotência) contribui para a cons- 
trução da representação que a família faz da hospitalização.

Esse sentimento aparece nos relatos:

"É horrível, porque ele tá ali doente, mesmo que seja pro bem dele é horrível ver ele nessa situação, toda hora colocando soro, mexendo, porque tá acostumado a tá brincando; e também pelos outros filhos que ficam em casa". (Maria da Penha)

"Difícil né. Muito difícil porque fico longe de tudo, sozinha. Uma hora fico nervosa, choro, depois me animo. A gente pelo filho faz tudo". (Maria Quitéria)

"Quando fiquei sabendo do internamento meu mundo acabou. Não foi fácil. Me deu uma tremedeira na hora". (Bertha Lutz)

Percebe-se nas falas a preocupação das mesmas com relação ao internamento, expressando a dificuldade, o impacto da notícia, a preocupação e o nervosismo gerado em todo esse período, devido ao diagnóstico e ao tratamento do paciente.

O período de hospitalização afeta todo o ciclo familiar, mas quando se trata de criança o quadro se agrava, pois é necessária a presença de um adulto que, na maioria das vezes, é a mulher: mãe, avó, tia. O papel de cuidadora faz com a que a mesma altere sua rotina e busque novas estratégias para lidar com as exigências que o processo de reabilitação da criança exige.

Crepaldi (1999), em seus estudos, pontua que o período de hospitalização obriga a família a se reorganizar e que a mulher precisa deixar suas outras funções suspensas (esposa, trabaIhadora, mãe de outros filhos, dona de casa).

Além dessas questões cabe destacar também o sentimento de culpa manifestado diante da hospitalização.

"Puxa vida será que não cuidei. As pessoas me falam 'Oh mulher, cuida bem dessas crianças!' Mais eu cuido bem delas". (Olga Benário)

A questão do cuidado direcionado para a mulher gera angústias e cobranças, principalmente diante de um quadro de doença ou não conformidade. O sentimento de culpa se intensifica quando, além do cuidado com a criança internada, há a preocupação com os demais filhos que ficam em casa com parentes, vizinhos ou até mesmo sem a presença de um respon- sável, como é possível identificar nas respostas dadas quando indagadas sobre com quem ficam os outros filhos:

"Com minha mãe. Não sei se tá com minha mãe ou com minha irmã. Acho que estão com minha irmã. É sempre ela que cuida". (Anita Garibaldi)

"As crianças ficam com a avó". (Maria da Penha)

"As crianças ficaram na Casa de Passagem com as tias pra eu cuidar do 'J'". (Olga Benário)

A vida doméstica na sua inteireza é afetada com a hospitalização tanto em relação ao cuidado com os filhos quanto em relação à sobrevivência dos mesmos, pois, a renda não é fixa e, cada dia que a criança fica internada, significa um dia a menos de ganho.

"[...] sou o pai e a mãe lá em casa. Eu que tô trabalhando. Fico aqui (no hospital) e fico sem ganhar. Quando chego em casa tem um monte de problema pra resolver, contas". (Maria da Penha)

"É difícil porque eu tenho outro filho pequeno que também tá doente. Ele tá com febre e eu não posso ficar do lado dele". (Bertha Lutz)

"Estou acostumada com meus filhos perto de mim. Não sei se estão cuidando bem, não sei se almoçaram, se estão no colégio". (Anita Garibaldi)

"Com meu primeiro filho foi diferente. Eu era casada, não tinha outros filhos. Mas agora tem os filhos, a casa, porque preciso ganhar pra sustentar a casa. Quase fico louca aqui (hospital) dentro. Dá vontade de pular a janela". (Maria da Penha)

As dificuldades vivenciadas pelas mulheres revelam mais uma vez a vulnerabilidade social em que as famílias se encontram, pois são famílias que não possuem condições materiais e imateriais para enfrentar os problemas do cotidiano, necessitando de uma rede de apoio tanto da parentela e da vizinhança quanto dos serviços socioassistenciais. São famílias que durante o período de hospitalização precisam ser acompanhadas pela rede de proteção através de uma ação intersetorial entre as políticas sociais (educação, saúde, assistência social) para que os agravos e riscos sociais sejam atenuados. 
Outro aspecto que precisa ser evidenciado é a questão de gênero que perpassa todos os discursos, colocando-se como uma categoria transversal no cotidiano das mulheres. As histórias de vida aqui compartilhadas revelam as contradições presentes na sociedade em relação às atividades femininas na esfera pública e privada.

Por maiores que tenham sido as mudanças, na sociedade atual, o espaço do lar e da família continua sendo um território prioritariamente feminino. De fato, as transformações na sociedade contemporânea acarretaram alterações muito restritas no papel social da mulher. Ao antigo modelo de mãe e esposa - foi apenas adicionado um outro, o de trabaIhadora, e as mulheres encontram-se, assim, atualmente, divididas entre os seus múltiplos papéis, buscando o melhor modo de conciliação entre eles. (PACHECO, 2005, p. 37).

O cuidado, portanto, enquanto atividade feminina desenvolvida na unidade doméstica, passa a ser estendido para a unidade de saúde. Nesse caso, para o hospital, como algo natural e inquestionável. Esses construtos acabam legitimando concepções moralistas e machistas que demonstram que a mulher tem o papel de única responsável pelo cuidado dos filhos, guardiã da harmonia familiar, gestora dos afetos e valores. Esse conteúdo, presente nas falas das entrevistadas, reflete o compromisso que a sociedade exige da mulher em relação às suas atribuições, principalmente enquanto cuidadora e protetora. No entanto, quando nos deparamos com famílias monoparentais femininas, como é o caso de duas mulheres entrevistadas, há o acréscimo de mais uma função, historicamente vinculada à figura masculina, que é o de provisão do sustento familiar, sem supressão de outras, o que potencializa a condição de vulnerabilidade dessas famílias.

\section{Considerações finais}

As representações sociais construídas pelas mulheres, sujeitos significativos dessa pesquisa sobre a hospitalização, são expressões do conhecimento elaborado pelas mesmas na sua realidade cotidiana, que sofre as determinações sociais, históricas e culturais presentes no contexto em que as mesmas estão inseridas (BOURGUIGNON, 2001, p.82).
Apreender as representações sociais exige, por parte do pesquisador, atenção ao aspecto cognitivo das mesmas, da experiência social dos sujeitos e das condições sócio-culturais em que se forjaram."Ou seja, são necessários articular os elementos afetivos, os sociais e os cognitivos e a sua exposição através da linguagem e da comunicação. Todos estes elementos permeiam a construção dos 'significados que o sujeito dá ao social." (BOURGUIGNON, 2001, p. 82).

A aproximação com essas mulheres, dos seus modos de vida, a escuta de suas inquietações, dores, sentimentos, ainda que de forma estreita pelo tempo de permanência no hospital, permitiu conhecer suas estratégias de sobrevivência e os impactos que o período de hospitalização da criança proporciona no cotidiano familiar. Não foi possível traduzir para esta pesquisa a linguagem indizível que acompanhou o processo de coleta de dados: os gestos, o silêncio, os olhares, as impressões, o íntimo de cada entrevistada. Elementos ricos de sentido e de possibilidades de análise das representações sociais da cotidianidade das famílias que não podem ser traduzidos em palavras.

Nas palavras de Júnior,

Muito ainda deverá ser dito sobre as coisas que não conseguem ser ditas. Sobre os sentimentos, impressões, terrenos íntimos que parecemos incapazes de expressar, para os quais as palavras fracassam, as frases se revelam ineficazes e, por maior que seja nosso repertório e esforço, somos levados a crer que podemos tão somente tangenciar, sem talvez ter alcançado nenhum deles. O indizível tem prestígio. Alimenta versos, desorienta escritores, atormenta filósofos da linguagem e estetas do sublime. (2007, p.31).

Este estudo, através das inferências produzidas, tornou possível ressignificar o exercício profissional que ora vinha sendo desenvolvido na unidade hospitalar, despontando um terreno fértil para o trabalho com famílias em uma perspectiva humanizadora, ética, criativa e propositiva. Provocou um repensar das concepções de família que subsidiam a construção de metodologias de trabalho e despertou o desejo de resgatar, tanto na intervenção quanto na investigação, a centralidade do sujeito na prática social. Sujeitos que têm uma história, não só porque têm nomes, 
endereços, cadastros institucionais, mas porque constroem na trama da vida cotidiana uma forma particular e coletiva de ser, pensar, agir, projetar, sentir, comunicar, amar, criar, transformar.

Ao conhecer os modos objetivos de vida dos usuários foi possível transcender às queixas dos mesmos, qualificando-as em demandas profissionais. O exercício profissional se fundamenta nas dimensões analítica e interventiva que exigem do mesmo a mobilização de conhecimentos teórico-práticos para a qualificação das respostas sócio-profissionais. Nesse sentido, tendo em vista a direção social construída coletivamente pela profissão, faz-se necessário a construção de conhecimentos/saberes críticos que reconheçam a integralidade dos sujeitos e as múltiplas determinações presentes na realidade concreta. Sem a compreensão das demandas, o profissional pouca chance terá de construir a relação teoria-prática e de ressignificar seu objeto de intervenção a partir da complexidade das relações sociais.

Esta pesquisa possibilitou alguns questionamentos com relação ao exercício profissional do assistente social: Como o profissional analisa e interpreta a realidade social? Que saberes têm sido construídos pelos profissionais na construção das respostas sócio-profissionais? Como ele conhece e reconhece as demandas profissionais? O que significa identificar as condições objetivas de vida dos usuários? Qual significado os profissionais têm atribuído ao trabalho que desempenham? O que significa situar o objeto de intervenção profissional? Que compreensão o profissional tem da questão social e suas múltiplas expressões? Qual a finalidade do exercício profissional?

Esses questionamentos não sugerem respostas imediatas e fragmentadas, mas permitem aos profissionais, em uma perspectiva de formação crítica permanente, construir um diálogo constante com a prática profissional e com a própria realidade para que seja possível pensar e intervir ética, política, teórica e tecnicamente.

Assim, entendemos que este estudo se constituiu como um passo inicial em direção ao conhecimento das condições objetivas de vida dos usuários atendidos pelo Serviço Social e à problematização das demandas profissionais quando se propôs a identificar as representações sociais dos sujeitos através do levantamento dos significados por eles atribuídos ao processo de hospitalização. Por isso, a necessidade de continuidade do estudo se faz presente no espaço institucional, para que seja possível forjar uma cultura profissional interdisciplinar e integral do cuidado e da produção da saúde que supere o modelo de atenção em saúde fragmentado e curativo.

Em contraposição, o trabalho em saúde, ao objetivar atender as necessidades de saúde dos sujeitos, nas suas singularidades, sem desconsiderar o contexto macroscópico, precisa considerar as formas de vida, o cotidiano vivido pelos sujeitos e as contradições presentes na realidade social. Esses determinantes são fundamentais para operar (ética, política e tecnicamente) outro paradigma de atenção à saúde.

\section{Referências}

AMBRAMOWAY, $M$. et al. Juventude, violência e vulnerabilidades social na América Latina: desafios para políticas públicas. Brasília: Unesco. BID, 2002. $192 \mathrm{p}$.

ARRUDA, A. Teoria das representações sociais e teoria de gênero. Caderno de Pesquisa, n.117, nov. 2002

BALSA, C. et al. (Org.). Conceitos e dimensões da pobreza e da exclusão social: uma abordagem transnacional. ljuí: Ed. da Unijuí, 2006.

BOFF, L. O cuidado essencial: princípio de um novo ethos. Inclusão Social, Brasília, v. 1, n. 1, p. 28-35, out./mar. 2005. Disponível em: <http://revista. ibict. br/inclusao/index.php/inclusao/article/viewFile/6/12>. Acesso em: 13 jul. 2011.

BOURGUIGNON, J. A. A pesquisa sobre representações sociais no contexto do Serviço Social.

Emancipação, ano 1, n. 1, p. 77-88, 2001.

CARVALHO, M do C. B. de. Famílias e políticas públicas. In: ACOSTA, A. R.; VITALE, M. A. F. (Orgs.) Família: redes, laços e políticas públicas. 4. ed. São Paulo: Cortez; Instituto de Estudos Especiais - PUC/ SP, 2008

CASTEL, R. A insegurança social: o que é ser protegido. Petrópolis: Vozes, 2005.

CREPALDI, M. A. Hospitalização na infância: representações sociais da família sobre a doença e a hospitalização de seus filhos. Taubaté: Cabral Universitária, 1999. 
FRIEDMANN, J. Empowerment: uma política de desenvolvimento alternativo. Oeiras: Celta:, 1996.

GIL, A. C. Métodos e técnicas de pesquisa social. São Paulo: Atlas, 1999.

HELLER, A. O cotidiano e a história. 4. ed.Rio de Janeiro: Paz e Terra, 1970.

IAMAMOTO, M.; CARVALHO, R. de. Relações sociais e Serviço Social no Brasil: esboço de uma interpretação histórico-metodológica. 8. ed. São Paulo: Cortez, 1991.

KALOUSTIAN, S.; FERRARI, M. Família brasileira: a base de tudo. São Paulo: Cortez, 1994.

MENEZES, W. N. de. Mulheres (in)visíveis: um estudo da representação social sobre a cidadania feminina. Emancipação, Ponta Grossa, ano. 7, n. 2, p. 87-114, 2007.

MINAYO, M. C. de S. Trabalho de campo: contexto de observação, interação e descoberta. In:

(Org.). Pesquisa Social: teoria, método e criatividade. Petrópolis: Vozes, 2007. (Coleção Temas Sociais).

MOSCOVICI, S. Representações sociais: investigação em psicologia social. Tradução de Pedrinho A. Guareschi. Rio de janeiro: Vozes, 2003.

NEVES, M. N. Rede de atendimento social: uma ação possível? Revista da Católica, Uberlândia, v. 1, n. 1, p. 147-165, 2009.

PACHECO, A. L. P. Mulheres pobres e chefes de família. 2005, 260 f. Tese (Doutorado em Psicossociologia de Comunidades e Ecologia Social) - Universidade Federal do Rio de Janeiro, Rio de Janeiro, 2005.

PEREIRA JUNIOR, L. C. O que diz o indizível. Mirandum 18. CEMOrOc Feusp - IJI Univ. do Porto - 2007. Disponível em: <http://www.hottopos.com/ mirand18 /lcosta.pdf>. Acesso em: 27 de novembro de 2013.

RICHARDSON, J. R. Pesquisa social: métodos e técnicas. São Paulo: Atlas, 1985.

SÁ, C. P. Representações sociais: o conceito e o estado atual da teoria. In: Spink, M. J. (Org.). O conhecimento no cotidiano. São Paulo: Brasiliense, 2004.

SARTI, C. A. Famílias enredadas. In: ACOSTA, A. R.; VITALE, M. A. F. (Orgs.). Família: redes, laços e políticas públicas. 4. ed. São Paulo: Cortez; Instituto de Estudos Especiais - PUC/SP, 2008.
SILVA, A. V. da. Vulnerabilidade social e suas consequências: o contexto educacional da juventude na Região Metropolitana de Natal. In: Encontro de Ciências Sociais do Norte Nordeste, 13, 2007, Maceió. Anais... Universidade Federal de Alagoas, 2007.

TRAD, L. A. B. A Família e suas mutações: subsídios ao campo da saúde. In: (Org.). Família contemporânea e saúde: significados, práticas e políticas públicas. Rio de Janeiro: FIOCRUZ, 2010. 